\title{
Facilitation of Student Resilience Through Educator Development of Critical Conscience
}

\author{
Pamela R. Rochester, PhD, LPC, NCC, LMHC \\ University of West Alabama, United States
}

Doi: $10.19044 /$ ejes.s.v6a9

URL:http://dx.doi.org/10.19044/ejes.s.v6a9

\begin{abstract}
Exposure to chronic trauma such as lifestyles of poverty, events of natural disaster, and acts of violence on individuals or groups continues to happen for educators and their students - if not via personal experience, via media-informed awareness. Critical conscience as increased awareness, understanding, and desire for advocacy is increased through experiential learning of pre-service educators as they engage in the lives of student populations they serve. A graduate course in work with multicultural populations routinely includes immersion experiences of pre-service educators in a population of students they teach and other than their own population. Selected student experiences and subsequent reflections were examined for results with relevance to application in amelioration of risks and promotion of resilience with chronic trauma. The study resulted in student reports of increased critical conscience. Based on literature reviews for the study, this enhanced critical conscience contributes to educator preparation for greater efficacy with intervention for amelioration of trauma impact and promotion of resilience development with future students whom they will teach.
\end{abstract}

Keywords: Critical conscience, educator preparation, trauma impact, resilience.

\section{Introduction:}

Traumatic experiences touch students and educators on a regular basis, making the phenomenon of chronic trauma an ongoing reality. The impact of a tramatic event spreads through the systems of life best depicted by Urie Bronfenbrenner's Ecological model of human development (Hollingsworth, 2018). These systems start at the place of the individual and moves outward through family/peers, neighborhoods, culture, and even time. The systems serve as a ripple effect of impact when trauma touches any system - rendering influence both inward and outward. 


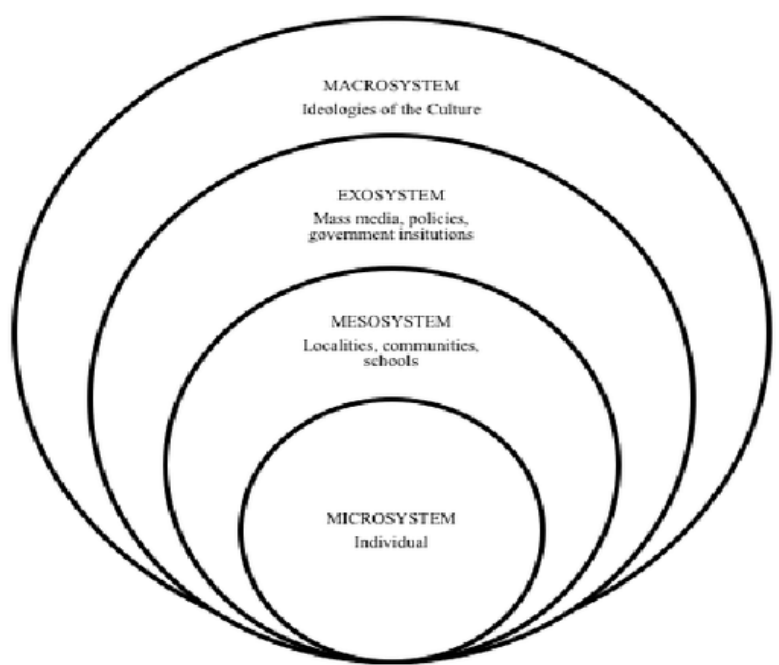

Figure 1. Urire Bronfenbrenner's Ecological Model of Human Development Source: Ecological Models of Human Development," by U. Bronfenbrenner, 1994, in

International Encyclopedia of Education (pp. 37-42), Oxford, UK: Elsevier.

Efficacy of educators is enriched as they enhance capacity to understand and communicate to the world of their students. A student worldview is framed by cultural parameters as well as student life experiences. Often these experiences involve chronic trauma such as living in poverty, living with a disability, or living in a mainstream culture setting that is not their own. Fregeau and Leir (2016) defined Critical Conscience as "an awareness and deep understanding of the social and political contradictions in the world that characterize the oppression of disenfranchised groups of people, especially the poor, and particularly as they apply to oneself" (p. 64). As educators engage with the lives of populations other than their own, they promote development of this critical conscience

Zhao, Meyers, and Meyers (2009) studied the experience of ten preservice American teachers studying abroad in China. They found five themes through their data analysis that serve as guides for other pre-service education students to increase efficacy of future service to students in experiences of chronic trauma. These themes were (1) understanding and respecting the individual students' culture, (2) developing empathetic dispositions to students not in the educator's cultural norm, (3) exchanging teaching strategies and resources, (4) reflection on both personal and professional growth, and (5) initiating a pro-active stance as change agents responsive to the worldview of students.

A key component of training for educators in support roles such as school counselors, school psychologists, and school social workers has been competence in multicultural helping. Recently, state level departments of 
education have expanded this emphasis to include all educators. Alexander, Kruczek, and Ponterotto (2005) noted that training for this competency has to go beyond just a course or just a textbook. Alexander, et al. designed a practical application component to more fully strengthen student development in multicultural competency. One of the key benefits was to help build student with adaptive functioning skills (p. 255).

Lack of experiential knowledge often lessens the capacity of educators to effectively support students in the face of chronic trauma. Alexander, et al. (2005) noted that immersion type experiences could help students move beyond the natural discomfort or fear of work with the unknown such as students in poverty, natural disasters, disabilities, or chronic exposure to violence. Even if an immersion experience was not afforded with every conceivable diversity, the experience of immersion into a different worldview could build capacity to increase comfort and anticipate work with a "difference."

\section{Literature Review}

Exposure to chronic trauma is almost a given for many of today's students. Examples are multiple locations across the world that qualify as areas of poverty and increase in chronic family or neighborhood stressors. As educators engage with students throughout these experiences, there is a crucial opportunity to promote resilience building with students through what Morrison and Allen (2007) term as "protective possibilities." Morrison and Allen note the important role that environment has in building student resilience. The school environment with its building, structure, faculty, and fellow students is important as an environment and can be controlled to much degree by the faculty and staff of the school. An environmental influence that students bring with them to school is that of family support and expectations. It is this influence that an educator cannot know through just vicarious exposure.

Differences in culture, lifestyles, or worldview can promote a barrier of pride in one's own framework and a temptation to discount the life framework of those who are different. Sheridan, Bennett, and Blome (2013) examined the precautions needed when transferring a training protocol from one cultural context to use within another cultural context. Sheridan, et al. noted that often this process of service to others outside one's own culture can carry a sense of "doing for" or "standing with" those who are of a different population (p. 819). The notion of Reverse Mission (Abram, Slosar, and Walls 2005) encourages educators to help promote resilience through learning from the others rather than trying to change the others through conversion to the educator's worldview. A key outcome of this approach is empowerment of educator efficacy. Sheridan, et.al reported that students experienced deeper 
learning of course concepts when they had opportunity to explore the meaning of these concepts on a personal level (p. 830). Immersion integration into cultures studied within a textbook fostered this deeper learning.

Winter and McEachern (1999) addressed ways to better meet education needs of underserved youth such as those living in poverty or other environments that might foster chronic trauma. One observation was the benefit of pre-service educators actually living among these underserved populations to "share locally valued activities and understand minority aspirations" (p. 713). Winter and McEachern conducted a study of pre-service educators in practicum placement among Canadian natives. The study found that efficacy was confirmed with the traditional model of practical experience of pre-service educators to acclimate to the classroom and school setting. In addition, efficacy was encouraged through those cultural and possible trauma parameters that pre-service educators had opportunity to explore and learn from.

\section{Critical Conscience}

Byrd (2012) noted that traditional teacher-centered instruction does not adequately prepare future educators for their inherent roles as change agents in the social needs of society. Some of this deficit is per emphasis on pressures for schools in testing and other accountability demands. Byrd suggested that pre-service training programs integrate opportunities for students to develop critical conscience as they increase awareness of problems and their perpetuation, analyze their function as future educators in problem resolution, and engage with the populations they serve to promote increased life efficacy for all.

Cassel (2001) discusses frameworks of change as first, second, and third forces of psychology. The first force has a focus on implementation of change per external prompting toward an individual. The second and third forces both focus on internal personal initiation of change, with the key difference being employment of free association techniques by practitioners within the second force to help an individual integrate whatever comes to mind. The third force seems to be more structured with the practitioner serving in a coaching role to support an individual's choice and decision.

Thus, promotion of critical conscience for educators in training could employ all three of these forces of psychology. An instructor could provide the external prompting as well as the coaching with the student generating the more specific nuances of a change process. This can be seen when students engage in real-world exposure to populations or issues with which they will work as educators. 


\section{Risk and Resilience Theory}

Military life poses presence of chronic trauma for families as they experience relocation, deployment of the military member(s), possible occurrence of Post Traumatic Stress Disorder, and post-deployment family reunion (Palmer, 2008). While each of these experience can provide traumatic influence on its own, there is often a larger framework present such as locales of poverty or civil unrest/war. There can also be individual trauma impact such as stress in family or school relationships. Palmer (2008) noted that these risk factors could be ameliorated through purposeful support to military families such as provision of support groups or psychoeducation.

West-Olatunji, Shure, Garrett, Conwill, and Rivera, (2008) noted the propensity for low-income African-American male adolescents to present lower academic progress than counterparts with most research on this having focus on the problem. West-Olatunji, et al. explored the intervention of strengths-based programs such as a Rites-of-Passage program to promote academic efficacy with this population. One of the key strengths of this program was exploration of environmental factors that could marginalize this population. A closing recommendation from the study was for educators to change their work with at-risk populations from problem-focus to a focus on strengths and the population's culture.

Mohamed and Thomas (2017) noted that often the school setting is the place in which students begin to build resilience that helps navigate the acute or chronic life traumas they may experience as both children and adults. They noted that learning more about both the risks and resilience capacity of their student populations, educators can better intervene with their students to promote life-long quality of resilience. Specific experiences within school were identified that both promoted building of resilience and hindered building of resilience. Resilience was enhanced through support networks such as friendships. Resilience was hindered through negative influences such as bullying, racism, social isolation, or exclusion per ethnic differences (p. 254). Educators are in a position to intervene for both promotion of the positive and minimization of the negative.

Sanders, Munford, \& Boden (2017) found similarity in the link between education aspirations and proximity of risks and resources with resilience for both students experiencing chronic trauma and students in a less traumatic developmental life path. Sanders, et al. confirmed the important role of educators in helping students to effectively use available resources for enrichment of educational outcomes. Their study indicated the importance of ecological level influences on both amelioration of risks and enhancement of resilience along the educational and life pathways of students. The educator and school was an integral part of the ecological influences. 


\section{Methodology}

As noted earlier by Alexander, et al. (2005), experiential learning through cultural immersion is vital to students in a course on multicultural counseling or other venues in education. Traditionally, a graduate course with orientation toward multicultural understanding and service is a core component of educator preparation programs such as school counseling. Such a course at a small regional university in the Southeastern United States includes a key assignment for students to engage in immersion within a culture other than their own to explore and learn from as they increase capacity to serve outside the parameters of their own cultural worldview. This presents opportunity to qualitatively study student report of impact on their development as future educators. This course is taught multiple times each school year with $80-100$ students per semester.

Students were free to select modality of experiential learning. This varied across student experiences. Students participated with daily life events of individuals, families, and communities. In most cases, learning included interviews.

Parameters of this immersion integration experience include student reflection on (1) Lessons learned about self in response to the experience, (2) Insight gained about the other worldview or culture, (3) Issues that could affect the student's engagement with members of the other culture, and (4) future changes in practice that the student would make in future engagement with members of that population. Excerpts from these reflections are shared that especially provide relevance to this experiential learning within the context of chronic trauma.

\section{Inner-City with Predominance of Minority Culture Students}

One student elected to spend several days in a soup kitchen that served a population that was poor and entrenched in a drug-infested culture, saying "I chose this culture to study as I teach children everyday which come from the same culture and background. I felt as though this will better prepare me as I enter the classroom every day and encounter the students which are born into this society. This will assist in filling the cultural gap between me and my students. I believe learning about others can help us to understand ourselves and be better world citizens. She also shared a reflection with one student from that culture, " A bunch of teachers here, they think they know what's wrong with us. But they don't know. If people want to help us, they have to see what we've been through, not from what their own experiences tell them."

Another student reported "I feel that I gained knowledge and understanding not only of just the African American culture, but an understanding of my students' lives. My eyes were opened to the fact that children have to act like adults and are responsible for their siblings. My heart 
broke at the thought of this student not being the only student I have, or have had in the past few years, that live this way. I physically saw the struggles these working mothers have to face on a daily basis in order to support their child/children and how it is up to them because of an absentee father(s). I was amazed as to how mature these older students can be outside of school.."

\section{Minority Student with Majority Culture}

As a teacher and aspiring counselor, I have the opportunity of working with and interacting with numerous cultural and ethnic groups. It is my goal to become more aware and more acceptable of the different cultures. These factors will enable me to have a more positive impact on my students, their parents, and their communities. Working in a diverse environment, I must work cooperatively with co-workers of different cultural and ethnic groups. This experience has enabled me to more thoroughly understand and to gain an appreciation for the diversity of my students and co-workers. This experience gave me an opportunity to become more aware of the traditions, ideals, and home life of the adults and children that I have the pleasure of encountering throughout my school day. I now know that reading about a specific culture in a textbook and observing that culture firsthand are completely different experiences. I also realize that individuals belonging to a particular culture may not always fit within the exact confines of cultural descriptions.

\section{The Culture of Disability}

One student elected to learn more about the world of disability, noting that the project ,challenges the writer to go into a culture different from his/her own to experience life in another's shoes. this endeavor would help me build a greater sense of empathy and better serve as an advocate for this population. Advocacy is important as historically this population has been discriminated against."

\section{General Reflections on Development of Critical Conscience}

Following are reflections from students that relate to development of awareness of those who are different, marginalized, or disenfranchised from the predominate culture of the pre-service educator.

The findings of this paper invistigated the impact of cultural differences on their learning experiences related to diversity issues after being exposed to an immersion with a different culture.

It is anticipated that ongoing research will be conducted to assess the dynmanic efficacy of a program to promote and sustain cultural competency among the University community. Rochester (2017)

1. With all the diverse backgrounds in this world, people rarely step outside of their comfort zones. I will be the first to admit that I was a little 
nervous about this project when I first read the requirements. I consider myself a people person, but I'm not one who just goes out of my way to impose in other people's lives. This task forced me to reconsider my willingness to be open to change and having "strangers", and in my inner circle.

2. This field experience enabled me to complete an assignment that displayed my understanding of racial and cultural dynamics in group and organizational life. Being placed into a cultural context with which I had little or no experiential familiarity encouraged me to be open to experiencing new things. Those new things have changed my perspective on people, and I hope that someday I can afford another student the opportunity to immerse themselves into my culture.

3. The inner glance generates knowledge unknown to most, while examining the integral parts of life for a teen that generate a course for the future with the grace and ease of a mature adult. Also shown, are the boundaries for beliefs and the foundations for which they are drawn. While these boundaries may exist, they are well respected and accepted as a part of life for the people of Belfast

4. One student chose to interact with a culture that he had very little familiarty and reflected, ,What would I do if confronted with an individual or family from this culture seeking counseling assistance? It would be neither fair nor ethical for me to accept such a case unless and until I would learn much more about these clients.

5. This immersion project will serve to not only highlight portions of my heritage, but will also allow me to connect with traditions of my students and their culture so I can better relate and understand the needs of the community in which I am working.

Table 1. Key Themes of Student Experiences

\begin{tabular}{|c|c|c|}
\hline Themes & $\begin{array}{l}\text { Critical } \\
\text { Component } \\
\text { (applies to all themes of } \\
\text { experience) }\end{array}$ & $\begin{array}{l}\text { Resilience \& Trauma } \\
\text { Application - numbers apply to } \\
\text { all themes of experience. }\end{array}$ \\
\hline $\begin{array}{lr}\text { Closing } & \text { Cultural } \\
\text { Knowledge } & \text { Gap } \\
\text { between pre-service } \\
\text { teacher \& } & \text { student } \\
\text { populations } & \end{array}$ & \multirow[t]{4}{*}{$\begin{array}{l}\text { Increased awareness and } \\
\text { deeper understanding of } \\
\text { social or political } \\
\text { contradictions characterizing } \\
\text { the populations of immersion } \\
\text { (Fregeau a\& Ler, 2016). }\end{array}$} & \multirow{4}{*}{$\begin{array}{l}\text { 1. Increased awareness of } \\
\text { purposeful support modalities } \\
\text { (Palmer, 2008). } \\
\text { 2. Movement from } \\
\text { problem focus to focus on } \\
\text { strengths of population (West- } \\
\text { Olatunji, et al. 2008). } \\
\text { 3. Knowledge of capacity } \\
\text { and needs of student risks and } \\
\text { resilience (Mohamed \& Thomas, } \\
\text { 2017). Contribution } \\
4 . \quad \text { to } \\
\text { ecological influences in }\end{array}$} \\
\hline $\begin{array}{l}\text { Experiencing what } \\
\text { student populations } \\
\text { experience }\end{array}$ & & \\
\hline $\begin{array}{l}\text { Increase awareness } \\
\text { and acceptance of } \\
\text { cultures of others }\end{array}$ & & \\
\hline & & \\
\hline
\end{tabular}




\begin{tabular}{|l|l|}
\hline $\begin{array}{l}\text { Increase breadth of } \\
\text { relationship comfort } \\
\text { zones }\end{array}$ & $\begin{array}{l}\text { amelioration of risks \& } \\
\text { enhancement of resilience } \\
\text { (Sanders, et al. 2017). }\end{array}$ \\
\hline $\begin{array}{l}\text { Improve relationship } \\
\text { and response to needs } \\
\text { of student } \\
\text { populations }\end{array}$ & \\
\hline
\end{tabular}

\section{Conclusion}

Exposure to chronic trauma such as lifestyles of poverty, events of natural disaster, and acts of violence on individuals or groups continues to happen for educators and their students - if not via personal experience, via media-informed awareness. Critical conscience as increased awareness, understanding, and desire for advocacy is increased through experiential learning of pre-service educators as they engage in the lives of student populations they serve. Immersion experiences of pre-service educators in a population of students they teach and other than their own population resulted in student reports of increased critical conscience. Based on literature reviews for the study, this enhanced critical conscience contributes to educator preparation for greater efficacy with intervention for amelioration of trauma impact and promotion of resilience development with future students whom they will teach.

\section{References:}

1. Abram, F.Y., Slosar, J.A., \& Walls, R. (2005). Reverse mission: A model for international social work education and transformative intranational practice. International Social Work, 48, 161-176.

2. Alexander, C.M., Kruczek, T, \& Ponterotto, J.G. (2005) Building multicultural competencies in school counselor trainees: An international immersion experience. Counselor Educator \& Supervision, 44, 255-266.

3. Byrd, D. (2012). Social studies education as a moral activity: Teaching towards a society. Educational Philosophy and Theory, 44(10), 1073-1079.

4. Cassel, R.N. (2001). Comparing the dynamics of second and third force psychology. Education, 122,131-134.

5. Fregeau, L, \& Leir, R. (2016). Two Latina teachers: Culture, success, higher education. Taboo: The Journal of Culture and Education, 2, 61-78

6. Hollingsworth, M.A. (2018). Theories of lifespan development. Acton, MA: ExanEdu.

7. Mohamed, S. \& Thomas, M. (2017). The mental health and psychological well-being of refugee children and young people: An 
exploration of risk, resilience, and protective factors. Educational Psychology in Practice, 33(3), 249-263.

8. Morrison, \& Allen, (2007). Promoting student resilience in school contexts. Theory into Practice, 46(2), 162-169.

9. Palmer, C. (2008). A theory of risk and resilience factors in military families. Journal of Military Psychology, 20(3), 205-217.

10. Rochester, P. (2017). Diversity Assessment to Learn Student's Attitudes and Awareness Concerning Diversity Prior to Enrolling in a Diversity Course. Journal of Management Science and Business Intelligence us.org/Journals/JMSBI/V2N2/Publish/V2N2_5.pdf http://www.ibii-

11. Sanders, J., Munford, R. \& Boden, J.M. (2017). Pathways to educational aspiration: Resilience as a mediator of proximal resources and risks. Kotuitui: New Zealand Journal of Social Sciences Online, 12(2), 205-220.

12. Sheridan, M.J, Bennett, S. \& Blome, W.W. (2013). Cultural humility and shared learning as hallmarks for international teaching: The SWEP experience. Social Work Education, 32(6), 818-833.

13. West-Olatunji, C., Shure, L., Garrett, M.T., Conwill, W. \& Rivera, E.T. (2008). Rites-of-pasto Learn sage programs as effective tools for fostering resilience among low-income African-American adolescents. Journal of Humanistic Counseling, Education, and Development, 47, 131-143.

14. Winter, E.C. \& McEachern, W.R. (1999). Subject specialization in teacher education; An experience in a Canadian native school. Education, 119(4), 713-722.

15. Zhao, Y., Meyers, L, \& Meyers, B. (2009). Cross-cultural immersion in China: Preparing pre-service elementary teachers to work with diverse student populations in the United States. Asia-Pacific Journal of Teacher Education, 37(3), 295-317. 